\title{
Educação e modernidade: sob as figuras do relógio e da tipografia*
}

\section{Education and modernity: under the figures of the clock and typography}

\author{
Kazumi Munakata**
}

\begin{abstract}
RESUMO
Comenius funda a escola moderna, numa cosmologia arcaizante, que concebe o universo como um sistema de espelhamentos sem fim. Mas é dessa concepção que emerge a valorização de dois artefatos da modernidade - o relógio e a tipografia -, que por sua vez constituirão o modelo da escola moderna, apresentando, entre outros aspectos, a seriação do tempo e o uso didático do livro.

Palavras-chave: Comenius, escola, livro didático.
\end{abstract}

\begin{abstract}
Comenius establishes the modern school, that he idealizes, in an archaic cosmology that conceives the universe as a mirroring system with no end. However from this conception emerges the valorization of two modernity artefacts - clack and typography - that, in their time, will constitute the model of modern school, presenting, among other aspects, serialization of time and didactic using of book.

Key-words: Comenius, school, didactic book.
\end{abstract}

\footnotetext{
* A versão inicial deste texto foi apresentada na sessão de comunicação coordenada "Educação e Modernidade", realizada no XX Simpósio Nacional de História, da Associação Nacional de História (ANPUH), em 1999. kazumi@ig.com.br

** Doutor em História da Educação, Professor do Programa, de Estudos Pós-Graduados em Educação: História, Política, Sociedade, da Pontifícia Universidade Católica de São Paulo.
} 
Idealizador da escola moderna, o morávio Comenius (15921670) parece, ele mesmo, arcaizante: em pleno século de Descartes (mas de Espinosa também...), imagina um Mundo que, longe de se dilacerar em res cogitans e res extensa, é formado por um continuum de similitudes, que nada mais são do que manifestações da Providência divina. Diz ele em Didática Magna, sua principal obra, cuja versão definitiva foi publicada em 1657:

Entendemos [...] pela palavra natureza a providência universal de Deus, ou seja, o influxo incessante da bondade divina para operar tudo em todos, ou seja, em cada criatura aquilo para que a destinou. Na verdade, o objetivo a sabedoria divina foi nada fazer em vão, isto é, nem sem qualquer finalidade, nem sem os meios adequados para conseguir esse fim. (p. 102.)

É porque o homem se encontra imerso nessa série de espelhamentos entre macrocosmo e microcosmo, que é possível uma Didática Magna que se apresente, diz seu subtítulo, como "Tratado da arte universal de ensinar tudo a todos":

O homem é chamado pelos filósofos microcosmos, resumo do universo, compreendendo, de modo obscuro, todas as coisas que se vêem por toda a parte amplamente espalhadas pelo universo (macro-cosmos). [...] Em conseqüência disso, a mente do homem que entra no mundo compara-se com muita razão a uma semente ou a um caroço, no qual, embora não exista ainda em ato a figura da erva ou da árvore, todavia, nele existe já de fato a erva ou a planta [...]. Não é necessário, portanto, introduzir nada no homem a partir do exterior, mas apenas fazer germinar e desenvolver as coisas das quais ele contém o gérmen em si mesmo e fazer-lhe ver qual a sua natureza. (p. 104.)

Ensinar é, então, seguir os passos da Natureza que, para atingir seu telos, finalidade, "espera o momento favorável"; "não realiza as

${ }^{1}$ Todas as citações, salvo indicações em contrário, são de Didática Magna, de Comenius. A versão aqui utilizada é da edição portuguesa, da Fundação Calouste Gulbenkian, cuja ortografia foi adequada para o padrão brasileiro. 
suas obras na confusão, mas procede distintamente"; "não dá saltos, mas procede gradualmente"; "não [...] abandona [um trabalho] senão depois de o haver terminado"; e "evita diligentemente as coisas contrárias e prejudiciais"; "caminha das coisas mais fáceis para as mais difíceis"; "não se sobrecarrega e contenta-se com pouco"; "não se precipita, mas procede lentamente"; "não produz senão aquilo que se revela imediatamente útil"; "faz todas as coisas uniformemente"; "liga todas as coisas com nexos contínuos"; etc. (p. 207 et seq.). Símile do proceder da Natureza, ensinar é, assim, operar tal qual fazem as aves em relação à procriação; as plantas, na germinação e no crescimento; os animais, na constituição da sua anatomia e fisiologia. É também imitar as atividades dos artífices: jardineiro cultivando as plantas; carpinteiro e arquiteto construindo edifícios; pintor ou escultor realizando a obra. Mas imitá-los é ainda imitar a Natureza, pois o que os artífices fazem não é mais do que seguir a disposição natural das coisas. Esclarece Comenius após enunciar que a "natureza começa todas as suas obras pelas coisas mais gerais e acaba pelas mais particulares":

\footnotetext{
Por exemplo: querendo, de um ovo, produzir uma ave, a natureza não começa por formar a cabeça, ou os olhos, ou as penas, ou as unhas; mas aquece toda a massa do ovo, e o movimento produzido pelo calor dá nascimento a uma rede de veias que oferece o esboço de toda a avezinha (a cabeça, as asas, os pés etc., em embrião), e, finalmente, pouco a pouco, cada parte se desenvolve até atingir a sua forma perfeita.

Imitando este fato natural, o arquiteto começa por conceber, na sua mente, o plano geral de todo o edifício [...]; e, em conformidade com esse plano, lança os fundamentos e levanta os muros, e finalmente, cobre a construção com o telhado. Depois disso, ocupa-se das partes mais pequenas [...]. (p. 218-219; sem grifos no original.)
}

A homogeneidade das similitudes, que não admite descontinuidades, estende-se não apenas da natureza aos artífices, mas também à arte e aos artefatos, que só são possíveis na medida em que imitarem adequadamente a natureza. Comparem-se, por exemplo, o peixe, o nadador e o navio: 
MUNAKATA, K. Educação e modernidade: sob as figuras...

Vê-se um peixe nadar na água? Para o peixe, é uma coisa natural. Se o homem o quiser imitar, terá necessariamente que recorrer a instrumentos e a movimentos semelhantes, ou seja, em vez das barbatanas ${ }^{2}$ deve estender os braços, e em vez da cauda, os pés, e movê-los do mesmo modo que o peixe move as suas barbatanas. Até mesmo os navios não podem construir-se senão sobre este modelo; em vez das barbatanas, estão os remos ou as velas, e em vez da cauda, está o leme. (p. 187.)

Em suma, "a arte nada pode fazer, a não ser imitando a natureza" (p. 187). A "arte universal de ensinar tudo a todos" é plenamente possível, mas só o é sob essa condição: a de jamais se desviar da natureza, cuja marca é a ordem:

Se procurarmos que é que conserva no seu ser o universo, juntamente com todas as coisas particulares, verificamos que não é senão a ordem, a qual é a disposição das coisas anteriores e posteriores, maiores e menores, semelhantes e dessemelhantes, consoante o lugar, o tempo, o número, as dimensões e o peso devido e conveniente a cada uma delas. Por isso, alguém disse, com elegância e verdade, que a ordem é a alma das coisas. Com efeito, tudo aquilo que é ordenado, durante todo o tempo em que conserva a ordem, conserva o seu estado e a sua integridade; se se afasta da ordem, debilita-se, vacila, cambaleia e cai. $O$ que é evidente por toda a espécie de exemplos tirados de toda a natureza e de arte. (p. 181.)

A noção de ordem possibilita, por fim, estabelecer continuidades ali onde a similitude apresenta-se mais como "dessemelhante". Se, por exemplo, um canhão ostenta tamanha capacidade destrutiva é porque seus efeitos

não provêm senão de uma ordem determinada dos maquinismos e da aplicação de substâncias ativas a substâncias passivas [...], da devida proporção da bomba, da suficiente quantidade de pólvora, da boa estrutura das balas e, finalmente, da boa direção dos tiros. Se falta uma só dessas coisas, todo o aparelho se torna inútil. (p. 183)

\footnotetext{
${ }^{2}$ Decididamente, Comenius não sabia nadar!
} 
De todos os artefatos, o relógio é um dos que mais fascina Comenius, que vislumbra entre este engenho e o universo uma perfeita similitude:

Observou-se o firmamento e verificou-se que havia um movimento perpétuo e que as várias revoluções dos astros produziam a variedade das estações que convêm ao nosso universo. Em consequiência disso, à sua imitação inventouse um instrumento capaz de reproduzir exatamente o movimento rotatório diário do firmamento e de medir as horas. E esse instrumento é composto de pequenas rodas, não somente para que uma seja arrastada pela outra, mas também para que o movimento possa continuar indefinidamente. Mas foi necessário compor este instrumento de peças móveis e de peças imóveis, precisamente como o mundo. Na verdade, no nosso instrumento, no lugar da terra, primeiro corpo fixo do mundo, são postas bases imóveis, colunas, guarnições, e no lugar das esferas móveis, do céu, as várias rodinhas. Mas como não se podia dar a uma roda a tarefa de girar sobre si mesma e de fazer girar, juntamente consigo, as outras (como o Criador deu aos astros a força de se moverem a si mesmos e de fazerem mover outros, juntamente consigo), foi necessário tomar emprestada da natureza a força geradora do movimento, ou seja, o movimento gerado ou pela gravidade ou pela liberdade. Com efeito, ou se prende um peso ao eixo cilíndrico da roda mestra e, enquanto o peso puxa para baixo, o eixo cilíndrico gira e faz girar a sua roda, e esta faz girar, juntamente consigo, outras, e assim sucessivamente; ou se faz uma longa mola de aço que, constrangida a volver em redor de um eixo cilíndrico, enquanto se esforça por regressar à liberdade e por se estender, faz girar o eixo cilíndrico e a sua roda. E para que o movimento do relógio não seja excessivamente rápido, mas lento como o do céu, encaixam-se outras rodinhas de modo que a última, aquela que, movida apenas por dois dentinhos, vai para a frente e para trás e faz tic-tac, tic-tac, representa o revezar-se da luz, que vai e vem, ou seja, o revezar-se dos dias e das noites. Àquela parte, porém, que deve dar o sinal da hora, ou do quarto de hora, ligam-se aparelhos, feitos segundo as regras da arte, que servem para aumentar ou diminuir o movimento, consoante a necessidade, precisamente do mesmo modo que a natureza, mediante o movimento das esferas celestes, faz surgir ou desaparecer o inverno, a primavera, o verão e o outono, cada um deles dividido em meses. (p. 188-190).

\section{A longa citação justifica-se não apenas porque o relógio mostra exemplarmente a relação macrocosmo-microscosmo no}


pensamento de Comenius ${ }^{3}$, mas principalmente porque este artefato, cujo uso à época estava se generalizando, é uma figura chave na instituição da escola moderna. Diz Comenius:

A arte de ensinar nada mais exige, portanto, que uma habilidosa repartição do tempo, das matérias e do método. [...] E tudo andará com não menor prontidão que um relógio posto em movimento regular pelos seus pesos. $\mathrm{E}$ tão suave e agradavelmente como é suave e agradável o andamento de um tal autômato. E, finalmente, com tanta certeza quanta pode obter-se de qualquer instrumento semelhante, construído segundo as regras da arte.

Procuremos, portanto, [...] dar às escolas uma organização tal que corresponda, em todos os pontos, à de um relógio [...]. (p. 186.)

\section{Isto implica uma distribuição ordenada do tempo em cada escola:}

Distribua-se meticulosamente o tempo, de modo que a cada ano, mês, dia e hora seja atribuída a sua tarefa especial.

[...] Observe-se estritamente esse horário e essa distribuição das matérias escolares, de modo que nada seja deixado para trás e nada seja invertido na sua ordem. (p. 223.)

Por outro lado, Comenius pensa também o funcionamento simultâneo de todas as escolas:

Será necessário, portanto, que todas as escolas públicas se abram e se encerrem uma vez por ano (temos razões para aconselhar que isso se faça no Outono, de preferência a fazer-se na Primavera ou noutra altura), para que, em cada ano, o programa de cada classe possa ser desenvolvido e todos os

\footnotetext{
${ }^{3}$ Se o relógio é um símile do universo, o homem também o é do relógio: "Com efeito, quanto ao corpo, construído com arte admirável, em primeiro lugar está o coração, que é móvel, fonte de vida e de atividade; dele os outros membros recebem o movimento e a medida do movimento. Mas o peso, ou seja, a verdadeira força motriz, e o cérebro, o qual, servindo-se dos nervos, como de cordas, faz andar as outras rodas (os membros) para diante e para trás. Na verdade, a variedade das operações interiores e exteriores corresponde à exata e perfeita correspondência dos movimentos do relógio" (p. 111).
} 
alunos $[\ldots]$, conduzidos em conjunto para a meta, sejam promovidos em conjunto à classe superior. (p. 462.)

Escolas funcionando todas ao mesmo tempo, ensinando as mesmas coisas, na mesma seqüência, simultaneamente, tal qual relógios marcando as horas em perfeita sincronia - eis o que NARODOWSKI (1993), examinando essas passagens de Comenius, denomina "simultaneidade sistêmica", isto é, "um mecanismo de equiparação da atividade escolar (sobretudo da escola comum ou pública) no que diz respeito a seu funcionamento em um período de tempo e em um espaço determinados" (p. 72).

A figura do relógio permite, assim, conceber a instituição de uma nova temporalidade educacional que, sendo uniforme e unívoca (ao menos tendencialmente), crie condições para ensinar tudo a todos. Tudo, na medida em que as matérias devem ser distribuídas em unidades de tempo segundo um plano prévio; a todos, pois doravante serão abstraídas diferenças de toda sorte (sociais, econômicas, de gênero etc.), de modo a nivelar os alunos reduzindo-os a destinatários de hora-aula. Nesse aspecto, o pensamento comeniano, apesar do seu viés arcaizante, já se encontra no registro de uma concepção mais moderna, abstrata e quantitativa, quase galilaica, do tempo.

Uma outra arte que Comenius invoca para traçar paralelos com "a arte de ensinar tudo a todos" é a tipografia, de invenção recente (segunda metade do século XVI). Ela certamente imita a natureza, pois o que a torna "tão perfeita" é

[...] a ordem observada na boa fabricação, fundição e acabamento dos tipos metálicos das letras, na sua distribuição nos caixotes, na sua disposição em páginas, na sua colocação sobre o prelo etc., na preparação, corte e dobragem do papel etc. (p. 184.).

A escola, por sua vez, deve ser o símile da tipografia:

Desejamos que o método de ensinar atinja tal perfeição que, entre a forma de instruir habitualmente usada até hoje e a nossa nova forma, apareça 
MUNAKATA, K. Educação e modernidade: sob as figuras...

claramente que vai a diferença que vemos entre a arte de multiplicar os livros, copiando-os à pena, como era uso antigamente, e a arte da imprensa, que depois foi descoberta e agora é usada. Efetivamente, assim como a arte tipográfica, embora mais difícil, mais custosa e mais trabalhosa, todavia, é mais acomodada para escrever livros com maior rapidez, precisão e elegância, assim também, este novo método, embora a princípio meta medo com as suas dificuldades, todavia, se for aceite nas escolas, servirá para instruir um número muito maior de alunos, com um aproveitamento muito mais certo e com maior prazer, que com a vulgar ausência do método. (p. 455.)

Nessa comparação, a "arte de ensinar" passa a denominar-se "didacografia" e os alunos são equiparados a papéis, pois é nos seus "espíritos [que] devem ser impressos os caracteres das ciências". O professor (ou a sua voz) equivale à tinta com que se imprime a alma dos alunos; a disciplina escolar é o prelo "que a todos dispõe e impele para se embeberem dos ensinamentos" (p. 458).

A metáfora tipográfica ocupa todo o capítulo denominado "Da organização universal e perfeita das escolas" (capítulo XXXIII), o que, de certa forma, é desconcertante, pois ali se fala mais da técnica de imprensa do que de escola propriamente dita. Em todo caso, não deixa de ser significativa a escolha da tipografia, um dos ícones da modernidade, como uma das figuras que caracteriza a escola.

A tipografia não acarreta simplesmente a produção em larga escala de livros. Mais do que isso, ela implica uma reviravolta no significado do livro. $\mathrm{O}$ que, até então, era primordialmente o depositário de segredos ocultos e inacessíveis, torna-se o seu oposto: possibilidade de novos conhecimentos. Toda a disputa em torno do Livro dos livros é emblemático disso: na ortodoxia católica, a Bíblia é um livro para não ser lido, a não ser por um pequeno grupo de especialistas, os únicos a disporem da competência para interpretá-lo; a Igreja reformada, ao contrário, proclama o sacerdócio universal, isto é, a capacidade que todos detêm de lê-lo (ou melhor, a obrigação de fazêlo). Não por acaso, a tipografia é uma invenção protestante e um dos primeiros livros a ser impressos, uma edição da Bíblia, em vernáculo.

A metáfora tipográfica de Comenius, ele mesmo um sacerdote da Igreja reformada, significa, então, muito mais do que propor uma educação em escala industrial, formando multidões. Ou melhor, se se 
propõe "ensinar a todos" é porque se supõe que o saber deva ser difundido a todos indistintamente, sem privilégios, do mesmo modo que a tipografia havia possibilitado tal difusão. A escola assim concebida faz parte do processo de dissolução da sociedade de ordens.

Por isso mesmo, ler e escrever tornam-se tópicos obrigatórios da educação escolar. Isso também significa que livro torna-se um dos itens indispensáveis nessa educação. Na metáfora tipográfica, Comenius afirma:

Os tipos são os livros didáticos e todos os outros instrumentos propositadamente preparados para que, com a sua ajuda, as coisas a aprender se imprimam nas mentes com pouca fadiga.

[...]

A analogia entre os tipos metálicos e os nossos livros didáticos (tais como nós queremos) é muito grande. Efetivamente, em primeiro lugar, assim como é necessário fundir, polir e adaptar os tipos, antes de se começar a impressão dos livros, assim também é necessário preparar os instrumentos do novo método, antes de começar a pôr em prática esse novo método. (p. 458-459.)

Comenius prossegue afirmando que é preciso grande abundância de livros didáticos; que eles devem conter "tudo aquilo que pertence à plena cultura dos espíritos"; que neles as matérias devem ser dispostos não de modo confuso, "mas repartido do modo mais distinto possível, em tarefas de um ano, de um mês, de um dia e de uma hora"; e que os alunos devem ter à disposição apenas "os livros didáticos de que têm necessidade na sua classe, para que os outros não sejam ocasião de distração e de confusão" (p. 459-460).

A escola de Comenius implica, assim, uma modalidade de educação que requer obrigatoriamente livros, e de um tipo específico deles. O livro - e mais especificamente, o livro didático - não foi uma "muleta" que se introduziu na escola quando ela ficou mal das pernas; era parte constitutiva, indispensável, da escola moderna desde seu nascedouro. ${ }^{4}$

\footnotetext{
${ }^{4}$ Por sinal, Comenius é, ele mesmo, autor de um livro didático: Orbis Sensualium Pictus (O mundo sensível em imagens), de 1658. A respeito dessa obra, comenta NARODOWSKI (1993):

“... é a matriz da qual se reproduziriam os livros com textos didáticos que formariam as crianças da sociedade ocidental moderna durante trezentos e cinqüenta anos. Do ponto de vista do
} 


\section{REFERÊNCIAS}

COMENIUS. Didáctica Magna. Tradução: Joaquim Ferreira Gomes. 3. ed. Lisboa: Fundação Calouste Gulbenkian, 1985.

Munakata, Kazumi. Produzindo livros didáticos e paradidáticos.São Paulo, 1997. Tese (Doutorado) - Programa de Estudos Pós-Graduados em Educação: História e Filosofia da Educação da Pontifícia Universidade Católica de São Paulo.

NARODOWSKI, M. Infância e poder. A conformação da pedagogia moderna. Campinas, 1993. Tese (Doutorado) - Faculdade de Educação da Universidade Estadual de Campinas.

Texto recebido em 09/04/2001

conteúdo, o livro didático expressa os temas definidos para o ensino em cada nível da escolaridade. Isto significa que o livro didático é uma mensagem construída ad hoc, e conseqüentemente, tanto sua elaboração quanto sua utilização somente são compreensíveis no contexto do processo geral de escolarização. Em outros termos, o livro didático não possui um valor literário ou científico autônomo: desde o século XVII e a partir da empresa comeniana, o texto [do livro didático] se legitima à medida que contribui eficientemente no processo de produção dos saberes escolares. No entanto, o texto possui um estilo literário e uma retórica singular, o que já pode ser vislumbrado no Orbis Sensualium Pictus. O livro didático constrói uma estética que lhe é própria. [...] Parece haver um tipo de coexistência necessária entre a escolarização moderna e o livro didático". 